\title{
DEVELOPMENT OF A PROTOTYPE MODEL FOR FULLY AUTOMATED SARAWAK LAYERED CAKE MACHINE
}

\author{
A.S.Z. Abidin*, Annisa. J, W.K. Tan, A.R.H. Rigit, J.S. Chong, M.A. Kiprawi and P.R. Johnapi \\ Department of Mechanical \& Manufacturing Engineering, Faculty of Engineering, Universiti Malaysia Sarawak, 94300 Kota \\ Samarahan, Sarawak, Malaysia, “Corresponding Author's, E-mail: zaasakura@,feng.unimas.my,jannisa@feng.unimas.my, \\ arigit@feng.unimas.my, adeng90@yahoo.com
}

Keywords: Prototype, Sarawak Layered Cake; Automatic Machine; Sectional-base mechanism; Simulation.

\begin{abstract}
Layered cake also known as kek lapis is very synonym to Sarawak and very famous souvenir to tourist who travels to Sarawak. The exclusive savour and colourful layered design attribute has secure its constant demand all the year especially during festive seasons. The products are not only catered for Sarawak but also exported to Peninsular Malaysia, Singapore and Brunei. The industry contributes almost RM 3 million a year to the entrepreneurs. However, the tedious traditional process is unable to cope with the demand. Manual process is highly dependent on labours and the labours skills has direct influence on the quality of cakes produced. The development follows systematic engineering design process. Concept of sectional base mechanism has been chosen for the machine. The automatic machine has includes all basic processes namely filling of mixture to the baking tray, baking, layered, pressing and cooling. The proposed model is expected to produce 216 moulds per day, which is $430 \%$ improvement from the current production rate (50 moulds). Estimated manufacturing cost is about RM 37,000 only. Copyright (C) 2014 BICET -All right reserved.
\end{abstract}

\section{Introduction}

Layered cake also known as kek lapis is very synonym to Sarawak and very famous souvenir to tourist who travels to Sarawak. The exclusive savour and colourful layered design attribute has secure its constant demand all the year especially during festive seasons. As number of tourists visiting Sarawak every year is increasing the demand for the cakes is also increasing. To remain competitive, the industry should go beyond the local market. Consequently, the productivity needs to be increased to ensure continuous supply of future demands. However, the tedious traditional process is unable to cope with the demand. Manual process is highly dependent on labours and the labours skills has direct influence on the quality of cakes produced. Majority of the kek lapis producers use traditional ovens with one worker attached to each oven along the time of operation. The oven capacity is limited that consequently limit the potential of the industry to grow. Therefore, the industry seeks for modern technology to improve the production rate and also standardize the quality of the cakes. This paper describes the development of an automatic cake layer machine that can improve productivity of the Sarawak Layered Cakes industry.

Layered cakes produce in Sarawak are not only catered for domestic demand but also exported to Peninsular Malaysia, Singapore and Brunei. The industry is able to generate almost RM 3 million a year income [1]. In 2009, there are 90 layered cake entrepreneurs registered under the Bumiputra Entrepreneur Development Unit, Department of Sarawak Chief Minister. All of them are fall under SMEs that have very limited financial capability. Most of the producers are using cooking gas oven that limit on the use of technological device such as thermostat and timer. Instead, layered is very tedious and time consuming process that require for skill workers. Each worker is attached to one oven and average production rate is 9 moulds per worker for an hour. Normally a cake house needs about 23 workers and the team has to work multiple shifts during peak seasons. Even the industry realized the importance of advanced technology to replace the tedious process, but until now there is no machine available in market that meets the unique needs of Sarawak layered cake process.

As compared to ordinary cakes, to produce Sarawak layered cake involved tedious processes. The production process involves the process of feeding, layered, baking, cooling and pressing. The whole processes are repeated for number of times. During layered process, each layer of the cake is baked and overlapped one after another up to 12 layers or sometimes even more. Each layer requires around 2-3 minutes of baking period before the subsequent layer. Before each new layer is applied, the cake needs to be taken out of the oven and must be cooled down, and then lightly pressed. Pressing the cake is necessary to remove all the trapped air within the cake. The process is very time consuming and complicated that needs close supervision throughout the process.

Based on the market survey conducted, there is no automatic machine for a complete process used in Sarawak layered cake industry yet. Some of big companies use automatic machine but limited to two layers only. The process of layered is also different from what has been practiced in Sarawak as the cake is completely baked before going through layered process. Sarawak layered cake also comes with varieties of cakes sometimes up to 60 different cakes at once that makes it very difficult to automate the production, as automatic production allow for minimum flexibility. 